Supplement of Biogeosciences, 15, 4353-4365, 2018

https://doi.org/10.5194/bg-15-4353-2018-supplement

(C) Author(s) 2018. This work is distributed under

the Creative Commons Attribution 4.0 License.

(c) (1)

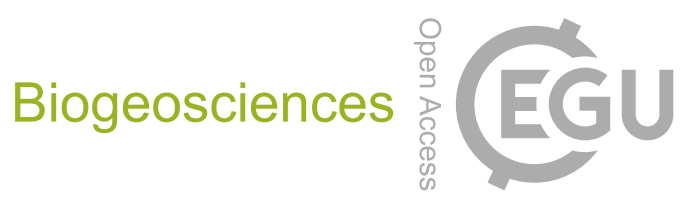

Supplement of

\title{
The Arctic picoeukaryote Micromonas pusilla benefits synergistically from warming and ocean acidification
}

Clara Jule Marie Hoppe et al.

Correspondence to: Clara Jule Marie Hoppe (clara.hoppe @ awi.de)

The copyright of individual parts of the supplement might differ from the CC BY 4.0 License. 
Table S1: Statistical results from two-way ANOVAs investigating the individual and interactive effects of temperature and $\mathrm{pCO}_{2}$ on all measured properties of $M$. pusilla.

\begin{tabular}{|c|c|c|c|c|}
\hline & & temp & $\mathrm{pCO}_{2}$ & temp x $\mathrm{pCO}_{2}$ \\
\hline \multirow[t]{2}{*}{$\mu$} & $\mathrm{F}$ value & 327.61 & 8.75 & 11.78 \\
\hline & $\mathrm{p}$ value & $<0.001$ & 0.001 & $<0.001$ \\
\hline \multirow[t]{2}{*}{ Chl $a$ quota } & F value & 1.15 & 1.16 & 17.96 \\
\hline & $\mathrm{p}$ value & 0.30 & 0.36 & $<0.001$ \\
\hline \multirow[t]{2}{*}{$\mathrm{C}$ quota } & F value & 24.01 & 0.55 & 9.88 \\
\hline & $\mathrm{p}$ value & $<0.001$ & 0.66 & $<0.001$ \\
\hline \multirow[t]{2}{*}{ N quota } & F value & 4.75 & 0.56 & 10.12 \\
\hline & $\mathrm{p}$ value & 0.05 & 0.65 & $<0.001$ \\
\hline \multirow[t]{2}{*}{$\mathrm{C}: \mathrm{N}$} & F value & 13.70 & 3.16 & 2.23 \\
\hline & $\mathrm{p}$ value & 0.002 & 0.06 & 0.12 \\
\hline \multirow[t]{2}{*}{ C:Chl $a$} & F value & 13.45 & 1.67 & 5.89 \\
\hline & $\mathrm{p}$ value & 0.002 & 0.21 & 0.01 \\
\hline \multirow[t]{2}{*}{ POC prod. } & F value & 356.17 & 7.10 & 29.28 \\
\hline & $\mathrm{p}$ value & $<0.001$ & 0.003 & $<0.001$ \\
\hline \multirow[t]{2}{*}{$\mathrm{Fv} / \mathrm{Fm}$} & F value & 0.26 & 1.33 & 0.07 \\
\hline & $\mathrm{p}$ value & 0.62 & 0.30 & 0.98 \\
\hline \multirow[t]{2}{*}{$\sigma_{\text {PSII }}$} & F value & 0.11 & 0.17 & 2.28 \\
\hline & $\mathrm{p}$ value & 0.75 & 0.92 & 0.12 \\
\hline \multirow[t]{2}{*}{$\tau_{\mathrm{ES}}$} & F value & 5.82 & 0.98 & 3.79 \\
\hline & $\mathrm{p}$ value & 0.03 & 0.43 & 0.03 \\
\hline \multirow[t]{2}{*}{$\mathrm{NPQ}_{\max }$} & F value & 0.17 & 8.02 & 0.86 \\
\hline & $\mathrm{p}$ value & 0.68 & 0.002 & 0.49 \\
\hline \multirow[t]{2}{*}{$\alpha$} & $\mathrm{F}$ value & 0.03 & 1.44 & 1.16 \\
\hline & $\mathrm{p}$ value & 0.87 & 0.27 & 0.36 \\
\hline \multirow[t]{2}{*}{$\mathrm{ETR}_{\max }$} & $\mathrm{F}$ value & 1.16 & 0.55 & 1.31 \\
\hline & $\mathrm{p}$ value & 0.30 & 0.66 & 0.31 \\
\hline \multirow{2}{*}{$\mathrm{EK}_{\mathrm{K}}$} & F value & 0.68 & 0.82 & 1.28 \\
\hline & $\mathrm{p}$ value & 0.42 & 0.51 & 0.32 \\
\hline
\end{tabular}


Figure S1: Growth rate constants (A) and POC production (B) of M. pusilla under low (filled symbols) and high temperatures (open symbols) as a function of $\left[\mathrm{CO}_{2}\right](n=3$; mean \pm 1 s.d.). Results from statistical analysis can be found in Table SI2.
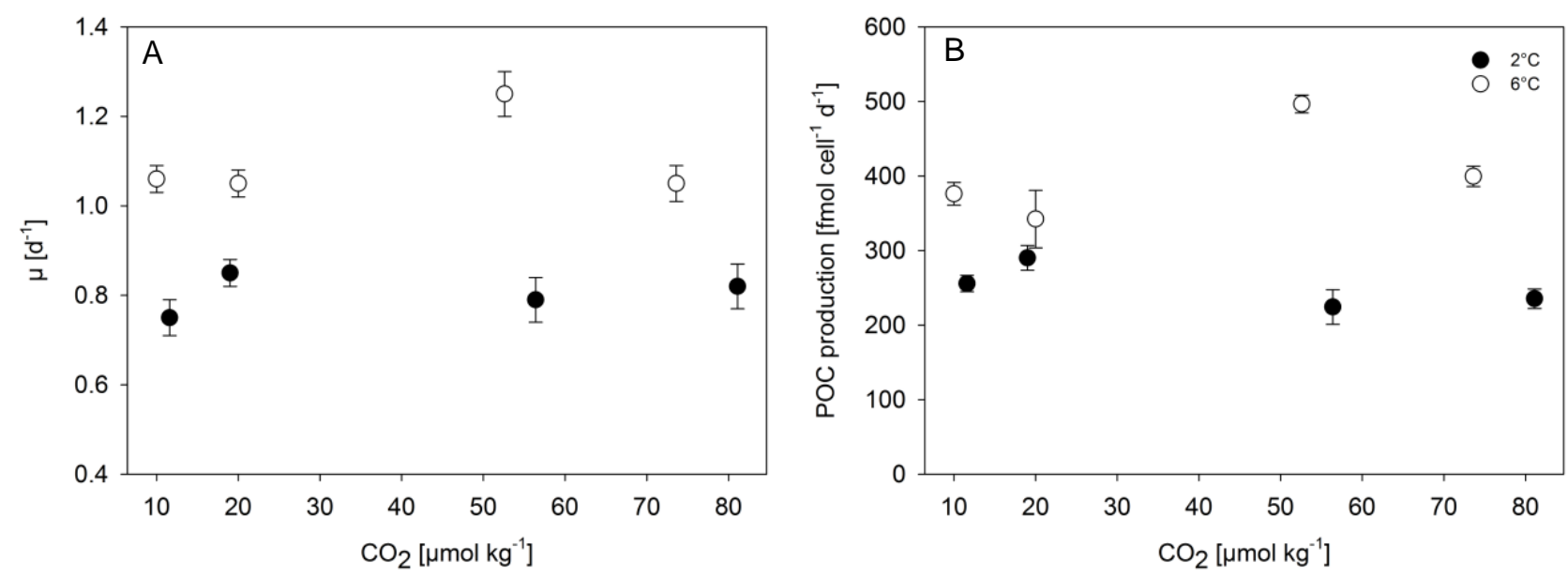